\title{
Determinación de la presencia de Listeria monocytogenes en queso fresco artesanal producido en el departamento de Cabañas
}

\author{
Ana Elizabeth Perlera de Escalante \\ Máster en Asesoría Educativa \\ Docente investigadora, Facultad Multidisciplinaria de Ilobasco, Cabañas \\ Universidad Católica de El Salvador, El Salvador \\ ana.perlera@catolica.edu.sv \\ Recepción: 23/07/2015 \\ Aceptación: 10/08/2015
}

\section{Resumen}

La inocuidad de los alimentos pasa de ser un requisito exigible por las normativas actuales y se convierte en una necesidad - inclusive para aquellos que producen en escala artesanal - de manera que se deben involucrar controles mínimos para los productos artesanales durante el proceso de elaboración. Los quesos frescos artesanales pueden contaminarse si no se practican buenas prácticas de manufactura, desde la producción hasta el almacenamiento, a fin que suponga riesgos por contaminación de Listeria monocytogenes, que es una bacteria que se encuentra en el ambiente y puede, incluso, soportar condiciones bajas de temperatura diferentes al resto de bacterias patógenas que afectan comúnmente a los alimentos.

Es sólo a través de los análisis efectuados a quesos artesanales del departamento de Cabañas, que se conoció la presencia de la bacteria en dos del total de 149 muestras estudiadas; sin embargo, en el análisis previo (67 muestras): enfocados en la identificación de coliformes, E. coli, Salmonella y St. aureus, como criterios de referencia en la contaminación a través de manipuladores, los límites observados en algunos casos se encontraron fuera de los establecidos por el RTCA $^{1}$ (67.04.50:08. Alimentos. Criterio Microbiológico para la Inocuidad de Alimentos).

En este estudio se trata de centrar la atención en los precedentes creados a partir de los resultados y su relación con la productividad de lácteos en la zona, que permita establecer parámetros de inocuidad y la estandarización de los métodos de producción artesanal.

Palabras clave: inocuidad, estandarización, Listeria monocytogenes, E. coli, Salmonella y St. aureus

\begin{abstract}
The food safety go from being an enforceable requirement by current regulations and becomes a necessity even for those who produce artisanal scale, so that should involve minimal controls for artisanal products during the manufacturing process. Artisan fresh cheeses can become contaminated if good manufacturing practices are not practiced, from production to storage, so that involves risks contamination of Listeria monocytogenes, a bacteria found in the environment and can even withstand cold conditions different from other pathogenic bacteria that commonly affect food temperature.

It is only through the analyzes made artisanal cheeses Department of Cabanas, the presence of the bacteria on two of the total of 149 samples studied was known, however in the previous analysis (67 samples) focused on the identification of coliforms, E. coli, Salmonella and St. aureus as benchmarks in pollution through manipulators, the limits observed in some cases were found outside established by the RTCA (67.04.50:.. 08 Microbiological criteria for Foods Food Safety).
\end{abstract}

This study is focusing on the precedents created from the results and their relation to productivity of dairy in the area, in order to establish safety parameters and standardization of methods of artisan production.

Keywords: safety, standardization, Listeria monocytogenes, E. coli, Salmonella and St. aureus

\section{RTCA: Reglamento Técnico Centro Americano}




\section{Introducción}

En la producción de quesos, el proceso de pasteurización de la leche es un efectivo tratamiento térmico para la destrucción de los microorganismos patógenos, según lo mencionan los autores Espinoza, A.; De la Torre, M.; Salinas, M. y Sánchez V. (2003). No obstante, la elaboración de quesos con leches no tratadas, han causado en muchos países daños a la salud, que se pueden convertir en enfermedades transmitidas por los alimentos (ETA'S); el autor utiliza este término para explicarlas como enfermedades de origen alimentario (...), Schöbitz R., Ciampi L., Nahuelquin Y. (2009). Estas son atribuidas principalmente a patógenos, algunos de ellos son: Staphylococcus aureus, Salmonella spp. y Bacillus cereus.

Durante los últimos diez a quince años se han aislado, además, otras bacterias denominadas «patógenos emergentes», que incluyen a bacterias tales como Listeria monocytogenes, de origen alimentario, y puede crecer en condiciones favorables en diferentes productos lácteos según lo estudiado por los autores Albarracín, F.; Sarmiento, et al (2006) y Bell, CH.; Kyriakides, A. (1998). Además del estudio sobre Escherichia coli O157: H7 que se vuelve importante como un marcador de la higiene en la manipulación de alimentos; aparte de ello, hay que resaltar que después del proceso de elaboración de los quesos, otras bacterias de origen láctico pueden acidificar el producto y crear condiciones de crecimiento mixto entre las bacterias, desfavoreciendo aún más las condiciones de consumo.

Es así como Ramírez, E., y Pineda S. (2010), mencionan que la Listeriosis, ${ }^{2}$ puede ocurrir en adultos y niños aún en buen estado de salud, constituyendo las mujeres embarazadas un grupo de alto riesgo, en las cuales esta bacteria puede inducir abortos o nacimientos prematuros, que tienen como secuelas la hidrocefalia y deficiencia mental. Según el autor Martino, T. et al. (2005), «tiene un prolongado período de incubación y sus manifestaciones clínicas son muy variadas, por lo que se dificulta el diagnóstico y se eleva la letalidad». Otro grupo altamente susceptible son las personas inmunocomprometidas y de la tercera edad.

En el departamento de Cabañas existen pequeños productores que trabajan bajo técnicas artesanales o caseras de elaboración de quesos, cuyas prácticas higiénicas no resguardan completamente la inocuidad del alimento, tanto en el procesamiento como en la conservación. Sin embargo, es imperativo realizar los análisis microbio-

2. Enfermedad producida por la bacteria Listeria monocytogenes. 
lógicos de rutina correspondientes siempre que la reglamentación vigente sugiera o haga pensar en la presencia de un agente patógeno específico en un alimento. Es así, como se vuelve importante prestar atención y preceder en un estudio sobre la determinación de presencia o ausencia de Listeria monocytogenes en quesos artesanales elaborados en el departamento de Cabañas, a su vez realizar el recuento de bacterias entéricas indicadoras como E. coli y Coliformes, y otras como St. aureus, Salmonella $s p p$, que muestra si los alimentos han estado sometidos a condiciones que pudieran haber permitido la llegada a los mismos y/o la multiplicación de agentes infecciosos o toxigénicos, constituyéndose en vehículo de transmisión de enfermedades; y a su vez, puedan ser reducidos mediante prácticas de higiene y sanitización adecuados para mejorar la inocuidad de los quesos que la población consume.

\section{Materiales y métodos}

El tipo de estudio se desarrolló de forma experimental, se tomó a los nueve municipios del departamento de Cabañas, para muestrear el queso fresco artesanal en estudio. Los análisis realizados se llevaron a cabo en el laboratorio de investigación, utilizando equipos de autoclave, incubadoras, micro- pipetas, homogenizador Stomacher, agitador vortex y agitador-hot plate, así como diferentes medios de cultivo para el aislamiento y detección de las bacterias en estudio.

En la investigación se procedió al análisis de 147 muestras de quesos elaborados de forma artesanal en diversos días de producción pertenecientes a nueve municipios el departamento de Cabañas, de las cuales se dividieron en dos etapas: en la primera se utilizaron 67 muestras para análisis de las bacterias en general; 3 y posteriormente, en la segunda etapa se tomaron 82 muestras para el aislamiento e identificación de la bacteria Listeria monocytogenes, para determinar su presencia o ausencia.

Los análisis se determinaron en el laboratorio de microbiología con diferentes equipos y medios de cultivo requeridos por la metodología de análisis. La toma de muestras se hizo a través de un muestreo al azar según describe para los alimentos el autor, Greenfield, H. y Southgate, D. (1992), donde los quesos frescos artesanales se consumen en diferente proporción, para lo cual se hicieron muestras individuales y en secciones de análisis de cinco a seis muestras por semanas para la fase preliminar como parte de un primer registro de inocuidad; en donde los resultados permitieron establecer cuáles fueron las condiciones iniciales a la previa

3. Análisis de aerobios mesófilos, coliformes, E. coli, St. aureus, y Salmonella spp., como indicadores de calidad de productos lácteos. 
identificación de Listeria monocytogenes. Posteriormente, hacia la segunda etapa de análisis, se realizaron aproximadamente de ocho a diez muestras por semana, en las cuales se identificaron coliformes, aerobios mesófilos, E. coli, St. aureus, Salmonella y Listeria monocytogenes. ${ }^{4}$

Para la detección cualitativa de la bacteria Listeria monocytogenes se procedió de acuerdo a los parámetros que establece el (RTCA 67.04.50:08), y se procedió de la siguiente manera:

- La muestra se homogenizó en el caldo con el empleo de una bolsa de Stomacher y homogenizador peristáltico. A continuación se inocularon, por siembra en superficie, dos placas con Agar Oxford y Agar Palcam, medios selectivos - diferenciales, estas se incubaron de $35-37^{\circ} \mathrm{C}$ hasta 48 horas.

- Detección cualitativa: Al caldo LEB inoculado con la muestra de alimento se incubo a $30^{\circ} \mathrm{C}$ durante 48 horas. Este caldo se realizó como aislamiento en placas con Agar Palcam y Agar Oxford, se seleccionaron colonias típicas y se realizó la confirmación mediante pruebas bioquímicas.
Los métodos de selección emplean un enriquecimiento selectivo en caldo, por ejemplo: caldo de enriquecimiento para Listeria (FDA); para el aislamiento de colonias en agares selectivos, por ejemplo, agar LPM, agar Oxford, agar Palcam. Estos medios selectivos contienen varias combinaciones de antibióticos y otros productos químicos selectivos/diagnósticos, por ejemplo, acriflavina, cicloheximida, ácido nalixidico, cefotetano, poliximina $\mathrm{B}$, fosfomicina, sulfato de colistina, cloruro de litio y esculina.

Las colonias que crecen en los agares selectivos y muestran la morfología típica de Listeria spp, en ese medio, son designadas como presuntas (sospechosas) Listeria spp, y se realiza una identificación a nivel de especie mediante el análisis de las características bioquímicas y hemolíticas.

El desarrollo de los métodos convencionales exige nuevas alternativas en la identificación precisa de bacterias patógenas. Los métodos alternativos propuestos para el caso, se trata de pruebas rápidas bioquímicas. Sin embargo, estos métodos son muy laboriosos y prolongados, obteniéndose los resultados para las muestras que no contienen Listeria (resultados negativos) tras tres o cuatro días.

4. Este análisis supone muchas variables para la identificación de la bacteria, puesto que en algunas ocasiones aunque esté presente no se identifica con facilidad. 
Si las colonias en un agar selectivo exhiben las características morfológicas típicas de Listeria spp., son necesarios de dos a siete días más para confirmar a estas colonias sospechosas como Listeria spp., e identificar que especie está presente. Por consiguiente, existe la necesidad de suplir los métodos convencionales con métodos más simples y menos laboriosos, que preferiblemente sean capaces de dar los resultados mucho más rápidamente que los métodos convencionales.

Cuando se selecciona cualquier método para su uso, deben considerarse los siguientes atributos:

- Sensibilidad

- Especificidad

- Simplicidad

- Robustez

- Fiabilidad

La necesidad de pruebas adicionales para confirmar resultados presuntivos, tiempo (en la práctica) y tiempo utilizado para obtener el resultado final:

- Necesidad de personal entrenado y/o equipamientos especiales

- Coste por ensayo

Según las pruebas descritas por el autor Bell, Ch. y Kyriakides, A. (1998), muchos test alternativos dependen de la presencia de un número mínimo de células diana para la detección fiable, y los procedimien- tos especificados para su uso en el kit o test de un fabricante, están diseñados para asegurar un resultado fiable. Para evitar falsos negativos o falsos positivos, siempre es importante leer y comprender la información técnica suministrada por el fabricante del kit/test, y seguir cuidadosamente las instrucciones para la realización de la prueba.

Los kits de identificación bioquímica son una de las formas más simples de los sistemas de ensayo para la identificación de $L$. monocytogenes que ahorran trabajo. Consisten en una batería de reacciones bioquímicas, que tienen lugar en cámaras de ensayo, ya formadas, suministradas en una unidad desechable.

Normalmente, tras la incubación y la incubación de las cámaras de ensayo, las reacciones se comprueban mediante un cambio concreto de color en el medio. Tras la verificación, se obtiene un perfil de microorganismo, que se utiliza para determinar la identidad, de las especies Listeria. El autor Bell, Ch.; y Kyriakides, A. (1998; p. 147), menciona la utilidad para identificación especifica de L. monocytogenes, puede ser necesario complementar los resultados obtenidos con un test CAMP y de hemolisis realizados por separado. 
Procedimiento de Análisis de Listeria monocytogenesen queso fresco artesanal

1. Seleccionar muestra $(25 \mathrm{~g})+$ caldo de Enriquecimiento para Listeria (LEB)

2. Incubar $30^{\circ} \mathrm{C}$ por 48 horas

3. Medio selectivo: desde LEB, tomar parte de la muestra enriquecida en el caldo LEB, utilizando un asa bacteriológica.

4. Sembrar a PALCAM con el suplemento selectivo.

5. Incubar $35^{\circ} \mathrm{C}$ por 48 horas.

Nota 1: Agua Destilada 1,000ml + PALCAM $68.8 \mathrm{~g}$, luego esterilizar a $121^{\circ} \mathrm{C} 15 \mathrm{mins}$.

Nota 2: Agregar A.D 2ml a una frasco del suplemento selectivo.

6. Enfriar a 50oC, y agregar suplemento selectivo $2 \mathrm{ml}$.

7. Sembrar a OXFORD agar con el suplemento selectivo, desde el caldo. LEB, contenido anteriormente con las muestras enriquecidas. (paralelo a la siembra en agar PALCAM)

8. Incubar $350 \mathrm{o}$ durante 48 horas.

Nota 1: Agua Destilada 1,000ml + Oxford agar $36.1 \mathrm{~g}$ luego esterilizar a $121^{\circ} \mathrm{C} 15 \mathrm{mins}$, Enfriar a $50^{\circ} \mathrm{C}$, y agregar el suplemento selectivo $10 \mathrm{ml}$.

Nota 2: Agregar (Ethanol5ml + A.D 5ml) a frasco del suplemento selectivo.

9. Medio de cultivo para analizar biocaracteres: Seleccionar una colonia sospechosa con un asa de aguja (lisa).
10. Sembrar a TSYEA (Trypto-Soy Yeast Extract Agar)

Nota1: Agua Destilada 1,000ml + TSYEA $30 \mathrm{~g}+6 \mathrm{~g}$ de Yeast Extract, luego autoclavar $121^{\circ} \mathrm{C} 15 \mathrm{mins}$ y se agrega a una placa de Petri $20 \mathrm{ml}$.

Nota2: observación con el telescopio con el luz inclinado 45 grado.

11. Se observa como luz verde azulado como la perla.

12. Inoculación en sistema rápido $\mathrm{CB}$ PLUS, Remel para Listeria.

13. Catalasa, hemolisis, VP, movimiento, xilosa, manitol laminosa, etc.

14. Observar el color del halo de la colonia y demás.

15. Procedimiento adaptado para análisis de laboratorio e identificación de Listeria monocytogenes [Donelly C. et al.( 1992), Hitchins A. D.,( 1995)]. 


\section{Procedimiento $^{5}$ de aislamiento e identificación de Listeria monocytogenes}
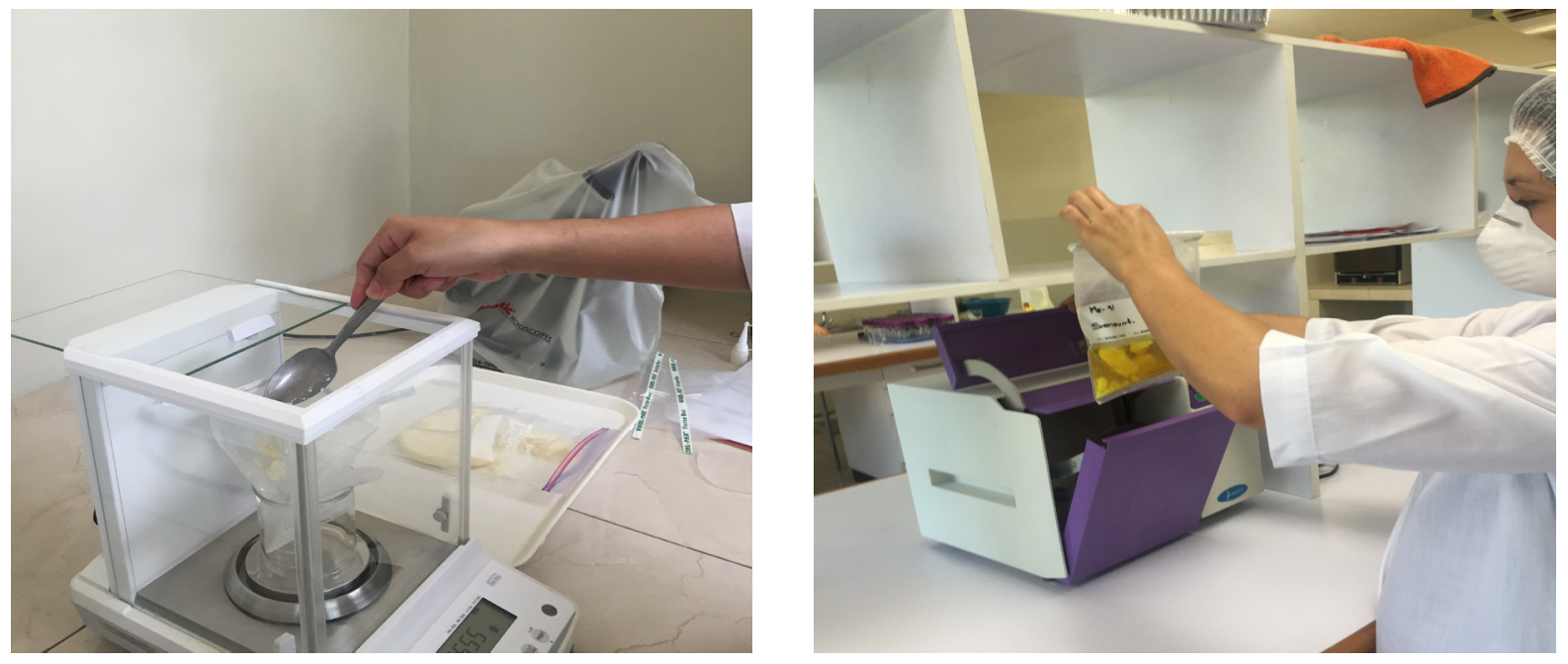

Figura 1. Proceso de pesaje de la muestra.

Figura 2. Homogenización de la muestra con caldo LEB.
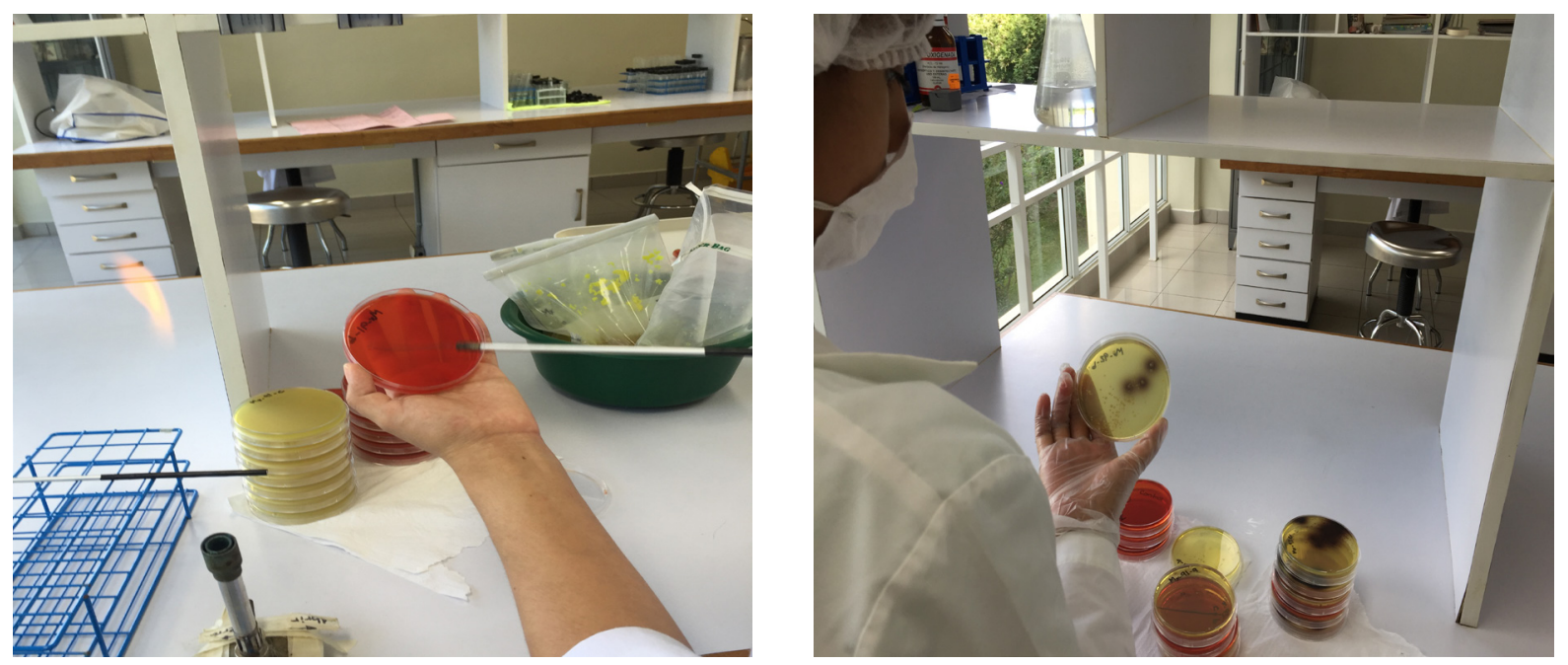

Figura 3. Siembra en agares cromogénicos oxford y palcam y posterior incubación.

Figura 4. Crecimiento de bacterias presuntas en agar cromogénico.

5. El procedimiento de análisis de Listeria monocytogenes, se realiza de acuerdo a los requerimientos que establecen las técnicas estandarizadas, como establece el autor Donnelly, C. et (1992). Compendium of methods for the microbiological examination of foods. 3rd Ed. Washington DC: American Public Health Association. pp. 637-663. De acuerdo con International Commission on Microbiological Specifications for Foods. (1996). Microorganisms in Foods. 5. Microbiological Specifications of Food Pathogens. Blackie Academic \& Professional, London., las bacterias deben ser aisladas según sus características y patogenicidad, para garantizar la efectividad de los resultados. 


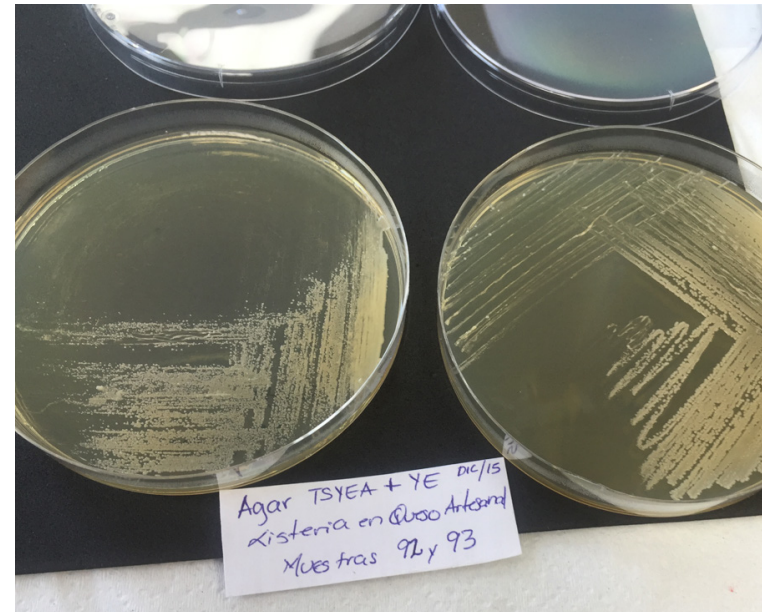

Figura 5. Colonias presuntivas aisladas en agar triptona soya agar + extracto de levadura.

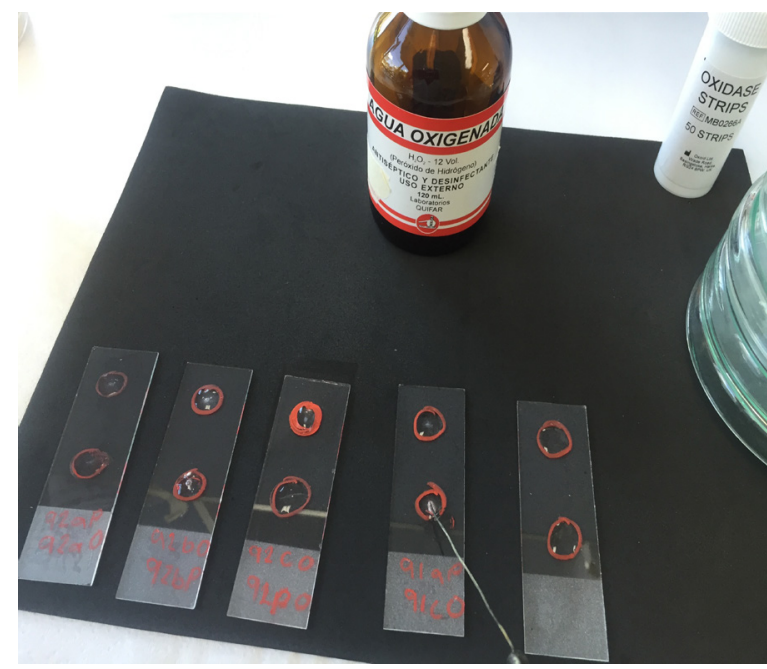

Figura 7. Prueba bioquímica de catalasa para muestras presuntivas de Listeria monocytogenes.

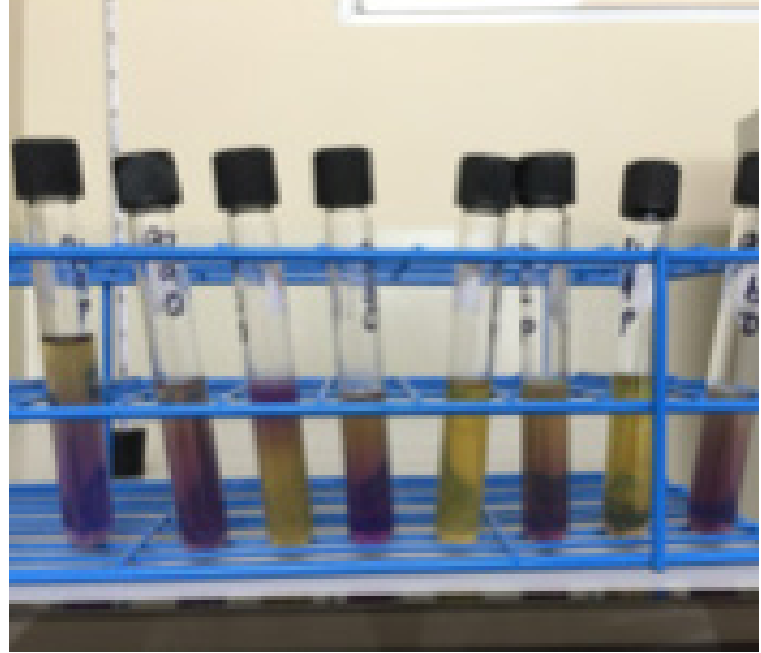

Figura 6. Pruebas bioquímicas de movilidad para confirmación de Listeria monocytogenes.

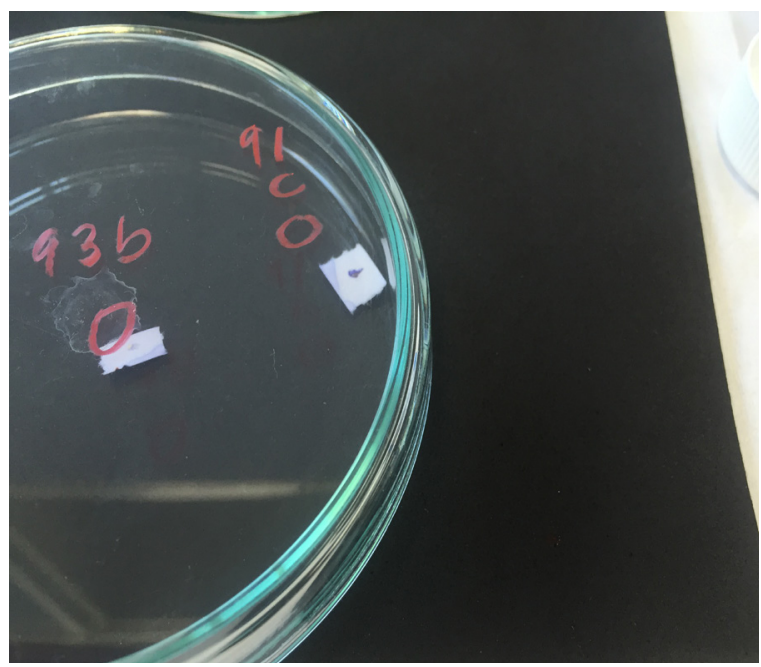

Figura 8. Prueba bioquímica de oxidasa para muestras presuntivas de Listeria monocytogenesnes. 


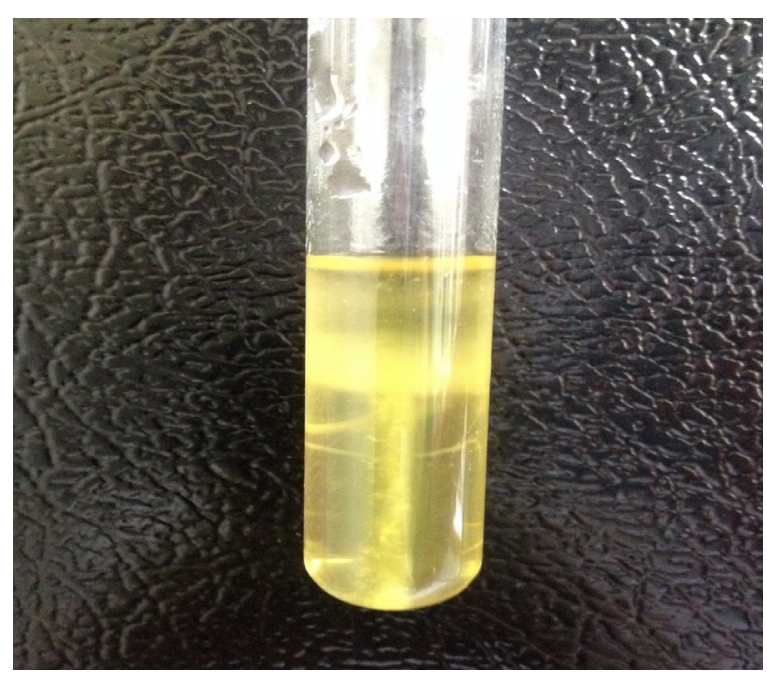

Figura 9. Prueba positiva para Listeria monocytogenes en agar movilidad.

\section{Resultados y discusión}

Las técnicas aplicadas para el desarrollo de la investigación consistieron en metodologías de análisis microbiológico para alimentos. Para el caso, al dividir el estudio en dos etapas de ejecución.

\section{a. Etapa I}

Esta etapa fue dirigida a un análisis preliminar que comprendió 67 muestras de queso fresco artesanal, analizando entre cinco y seis muestras cada semana. Estas fueron provenientes de los diferentes municipios del departamento de Cabañas. El enfoque de análi-

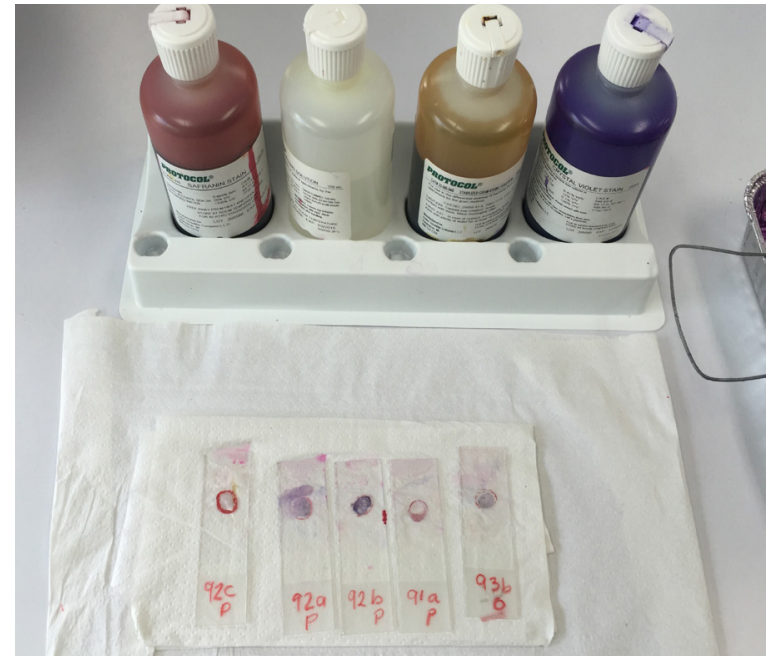

Figura 10. Láminas de tinción al gram, para la observación típica de la morfología de Listeria monocytogenes.

sis fue dirigido hacia un estudio general de las condiciones inocuas ${ }^{6}$ del producto elaborado.

En figura 11, se observa el total de muestras analizadas en el departamento de Cabañas, dentro del muestreo realizado para la primera etapa. El mayor porcentaje corresponde al municipio de Ilobasco; esto se debe a que la zona posee influencia en la comercialización de productos lácteos, seguido por el municipio de Ciudad Dolores, de acuerdo a la preferencia de los consumidores para la compra de productos lácteos.

6. Hace referencia a los factores que determinan las condiciones en las cuales fueron producidos los alimentos, actualmente existen lineamientos que determinan los procesos para garantizar que los ambientes libres de patógenos a través de la implementación de prácticas higiénicas según establece de acuerdo a Codex Alimentarius, (2007) Directrices Sobre la Aplicación de Principios Generales de Higiene de los Alimentos para el Control de Listeria monocytogenes en los Alimentos. Recuperado de: http://www.codexalimentarius.net/search/advanced.do?lang=es. 


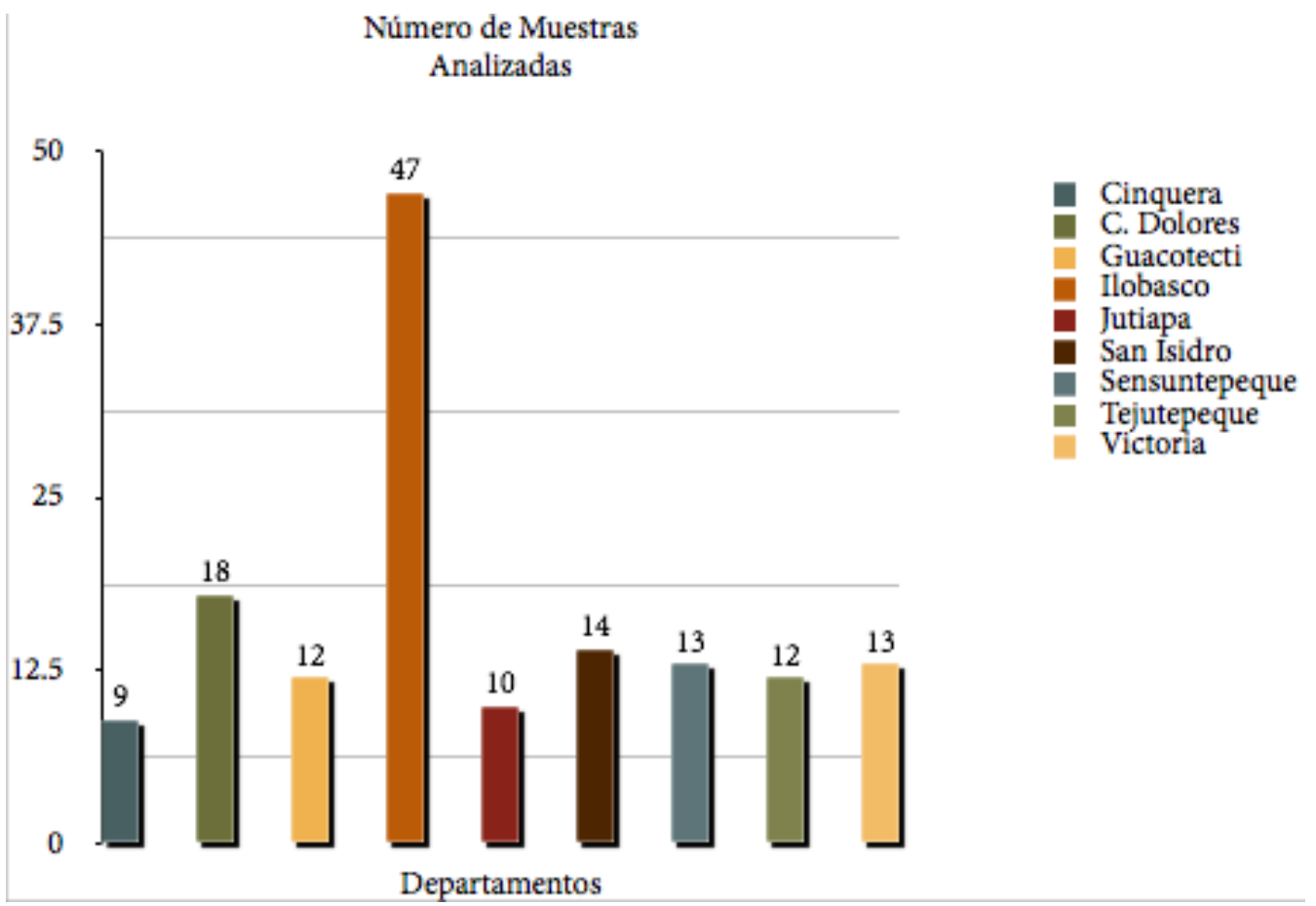

Figura 11. Porcentaje total de muestras analizadas por cada municipio del departamento de Cabañas.

En la siguiente tabla representa el conteo de aerobios mesófilos, durante la etapa I de análisis para el comportamiento de muestras de queso fresco artesanal. La frecuencia más alta en el conteo de aeróbico mostrado en la figura, pertenece al número más bajo de unidades formadoras de colonias por gramo de muestra.

Tabla 1. Resultados de aerobios mesófilos, etapa I de análisisñas.

\begin{tabular}{|l|l|l|l|l|l|l|}
\hline \multirow{2}{*}{$\begin{array}{c}\text { Municipio de } \\
\text { Cabañas }\end{array}$} & $\mathbf{0}-\mathbf{2 0 0}$ UFC/g & $\begin{array}{l}\mathbf{2 0 1}-\mathbf{1 0 0 0} \\
\mathbf{U F C / g}\end{array}$ & $\begin{array}{l}\mathbf{1 , 0 0 1}-\mathbf{2 , 0 0 0} \\
\text { UFC/g }\end{array}$ & $\begin{array}{l}\mathbf{2 , 0 0 1}-\mathbf{7 , 0 0 0} \\
\text { UFC/g }\end{array}$ & $<7000$ UFC/g \\
\hline Cinquera & 0 & 1 & 0 & 0 & 0 \\
\hline Dolores & 0 & 0 & 0 & 0 & 8 \\
\hline Guacotecti & 0 & 3 & 0 & 1 & 0 \\
\hline Ilobasco & 18 & 6 & 2 & 5 & 0 \\
\hline Jutiapa & 2 & 0 & 0 & 0 & 0 \\
\hline San Isidro & 3 & 2 & 1 & 0 & 0 \\
\hline Sensuntepeque & 4 & 1 & 0 & 0 & 0 \\
\hline Tejutepeque & 2 & 1 & 1 & 0 & 0 \\
\hline Victoria & 2 & 3 & 0 & 0 & 0 \\
\hline Total casos & 31 & 17 & 4 & 6 & 8 \\
\hline
\end{tabular}

La tabla 2 se resalta el comportamiento de la muestras en relación al conteo de E. coli, en quesos artesanales, del cual en un solo caso presentó un valor mayor a cien $\mathrm{UFC} / \mathrm{g}$, de forma que la incidencia en contaminación se reduce a valores mínimos, permitidos por la normativa. (RTCA 67.04.50:08 Alimentos. Criterios Microbiológicos para la Inocuidad de Alimentos).\} 
Tabla 2. Resultados de la identificación de E. coli, en quesos artesanales, relacionados a la etapa I de análisis

\begin{tabular}{|l|l|l|l|l|}
\hline \multirow{2}{*}{$\begin{array}{c}\text { Municipio de } \\
\text { Cabañas }\end{array}$} & $\mathbf{5}-\mathbf{2 9}$ UFC/g & $\mathbf{3 0}-\mathbf{5 0}$ UFC/g & $\mathbf{5 1}-\mathbf{1 0 0}$ UFC/g & $<\mathbf{1 0 0}$ UFC/g \\
\cline { 2 - 6 } & 1 & 0 & 0 & 0 \\
\hline Cinquera & 0 & 0 & 0 & 8 \\
\hline Dolores & 4 & 0 & 0 & 0 \\
\hline Guacotecti & 29 & 2 & 0 & 0 \\
\hline Ilobasco & 2 & 0 & 0 & 0 \\
\hline Jutiapa & 5 & 1 & 0 & 0 \\
\hline San Isidro & 5 & 0 & 0 & 0 \\
\hline Sensuntepeque & 5 & 0 & 0 & 0 \\
\hline Tejutepeque & 4 & 0 & 0 & 0 \\
\hline Victoria & 5 & 3 & 0 & 8 \\
\hline Total casos & 55 & & & \\
\hline
\end{tabular}

En la tabla 3, la detección cuantitativa para coliformes fecales, realizada en la primera etapa, muestra que la mayoría de los casos mantuvieron valores bajos de UFC por gramo, teniendo en cuenta que las muestras son de procedencia artesanal.

Tabla 3. Resultados de coliformes totales, etapa I de análisis

\begin{tabular}{|l|l|l|l|l|}
\hline \multirow{2}{*}{$\begin{array}{c}\text { Municipio de } \\
\text { Cabañas }\end{array}$} & $0-59$ UFC/g & $60-100$ UFC/g & $\begin{array}{l}101-200 \\
\text { UFC/g }\end{array}$ & $\begin{array}{l}201 \\
\text { UFC/g }\end{array}$ \\
\cline { 2 - 6 } & 1 & 0 & 0 & 0 \\
\hline Cinquera & 8 & 0 & 0 & 0 \\
\hline Dolores & 4 & 0 & 0 & 0 \\
\hline Guacotecti & 23 & 4 & 2 & 2 \\
\hline Ilobasco & 2 & 0 & 0 & 0 \\
\hline Jutiapa & 6 & 0 & 0 & 0 \\
\hline San Isidro & 5 & 0 & 0 & 0 \\
\hline Sensuntepeque & 5 & 0 & 0 & 0 \\
\hline Tejutepeque & 4 & 0 & 0 & 0 \\
\hline Victoria & 5 & 4 & 2 & 2 \\
\hline Total casos & 58 & & & \\
\hline
\end{tabular}


En la siguiente figura se aprecia el comportamiento de la bacteria Salmonella spp, según el municipio de procedencia, para el caso, del total de la muestras de la primera etapa, se ven reflejados dos casos positivos para las muestras de queso artesanal.

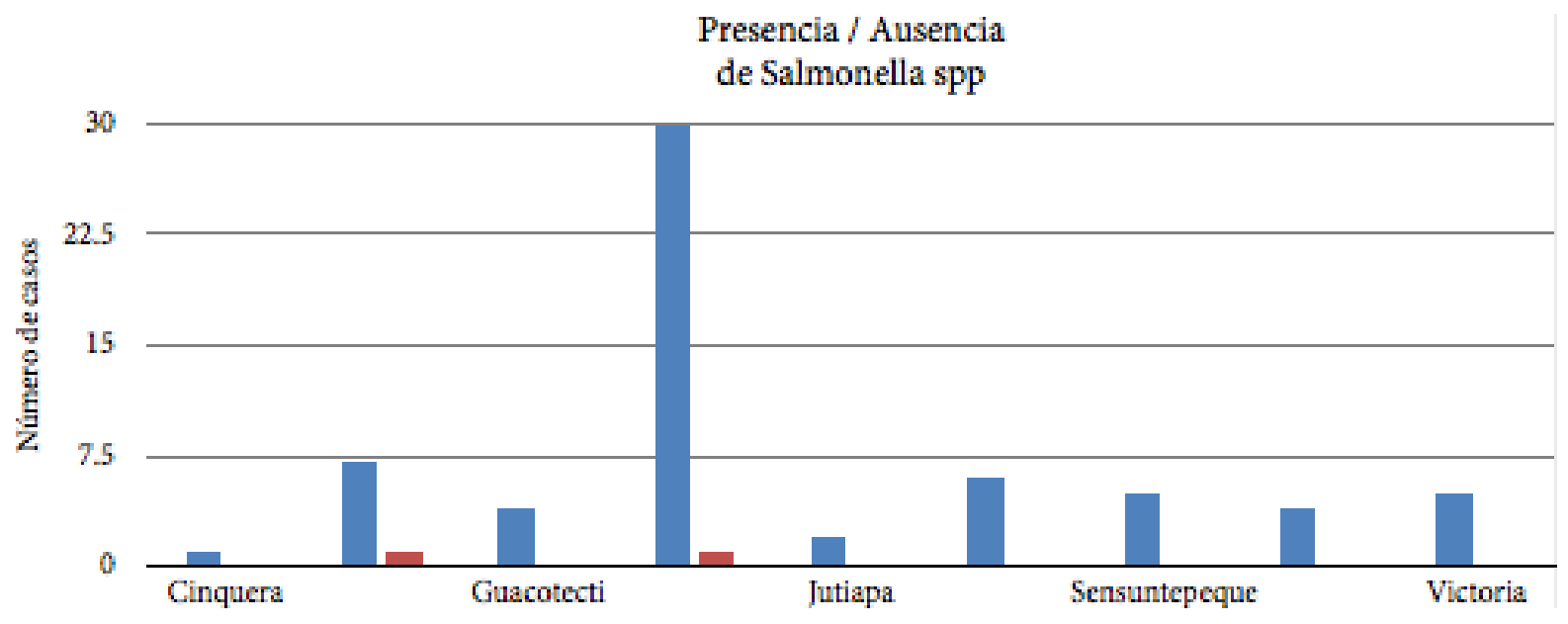

Figura 12. Comportamiento en la detección de Salmonella spp., etapa I de análisis.

En la figura 13, se muestra el comportamien- muestreados, la incidencia de los casos es soto de las muestras de queso fresco artesanal, lamente de uno de 67 muestras en total, para respecto a la identificación de St. aureus, se la etapa I observa según los Municipios que fueron

\section{Presencia / Ausencia \\ St. Aureus}

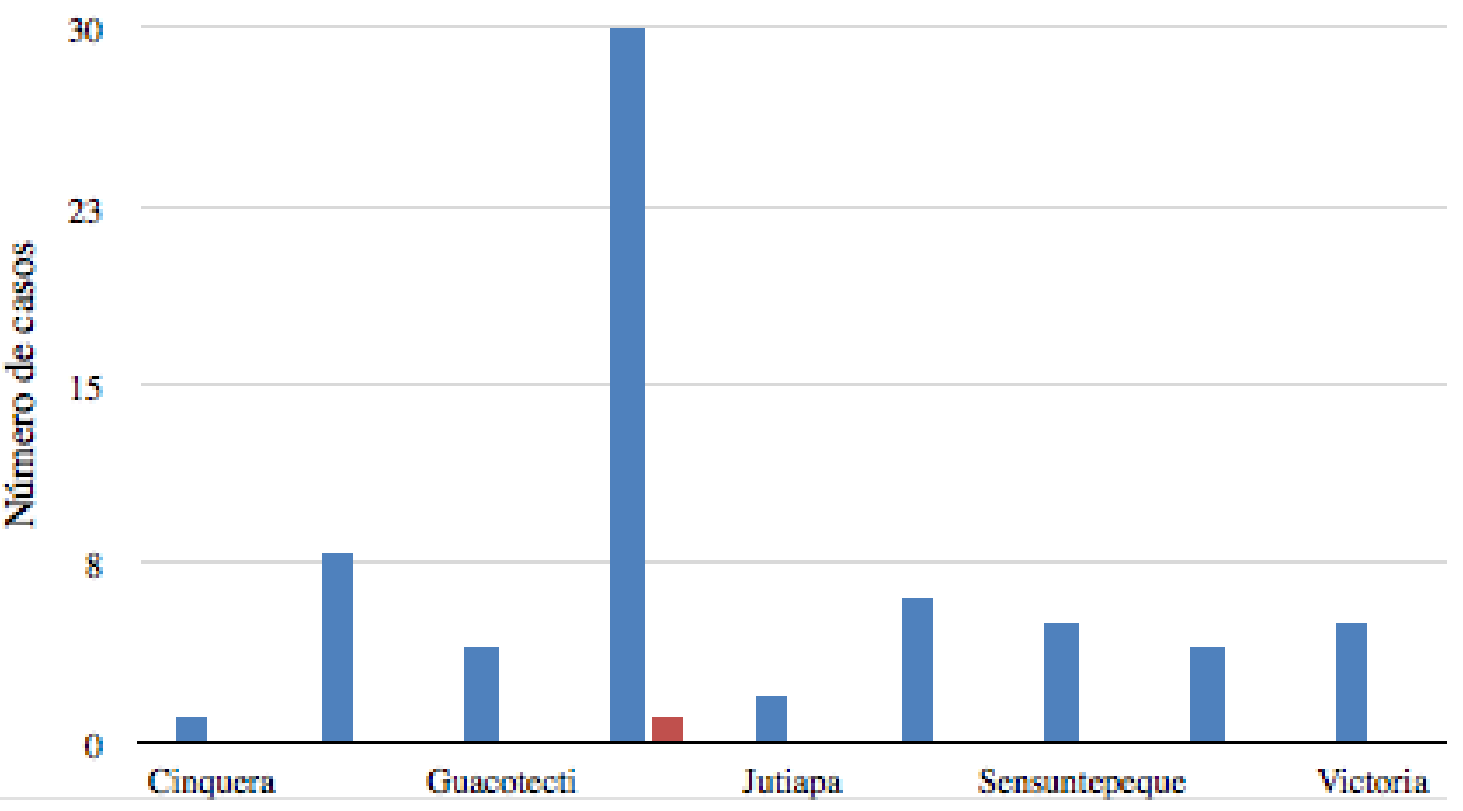

Figura 13. Comportamiento en la detección de St. aureus, etapa I de análisis. 


\section{b. Etapa II}

En la segunda etapa de análisis respecto a la investigación sobre la presencia de Listeria monocytogenes, se analizaron 82 muestras de los diferentes municipios del departamento de Cabañas, para las cuales se procedió con la identificación de bacterias aerobias mesófilas, E. coli, y Listeria monocytogenes, de las cuales se presentan a continuación:
En los resultados de la tabla 4, se observa la incidencia de casos para el conteo de aerobios mesófilos en las muestras de queso fresco de la II etapa de análisis de la investigación. Los datos reflejan que las unidades formadoras de colonias, se encuentran en un rango menor a 200UFC/g. Esta tendencia muestra como el queso fresco a pesar de su procedencia artesanal, mantiene niveles aceptables respecto al recuento aeróbico.

Tabla 4. Resultados de análisis de aerobios mesófilos, etapa II de análisis

\begin{tabular}{|l|l|l|l|l|l|l|}
\hline \multirow{2}{*}{$\begin{array}{c}\text { Municipio de } \\
\text { Cabañas }\end{array}$} & $\mathbf{0}-\mathbf{2 0 0}$ UFC/g & $\begin{array}{l}\mathbf{2 0 1}-\mathbf{1 0 0 0} \\
\text { UFC/g }\end{array}$ & $\begin{array}{l}\mathbf{1 , 0 0 1}-\mathbf{2 , 0 0 0} \\
\text { UFC/g }\end{array}$ & $\begin{array}{l}\mathbf{2 , 0 0 1}-\quad \mathbf{7 , 0 0 0} \\
\text { UFC/g }\end{array}$ & $<7000$ UFC/g \\
\hline Cinquera & 8 & 0 & 0 & 0 & 0 \\
\hline Dolores & 5 & 5 & 0 & 0 & 0 \\
\hline Guacotecti & 8 & 0 & 0 & 0 & 0 \\
\hline Ilobasco & 16 & 0 & 0 & 0 & 0 \\
\hline Jutiapa & 8 & 0 & 0 & 0 & 0 \\
\hline San Isidro & 4 & 4 & 0 & 0 & 0 \\
\hline Sensuntepeque & 8 & 0 & 0 & 0 & 0 \\
\hline Tejutepeque & 7 & 1 & 0 & 0 & 0 \\
\hline Victoria & 5 & 2 & 1 & 0 & 0 \\
\hline Total casos & 69 & 12 & 1 & 0 & 0 \\
\hline
\end{tabular}

En la tabla 5 se muestran los resultados del conteo de E. coli, para las muestras de la II etapa de investigación. Del total de muestras, once casos se encuentran fuera de lo especificado por la normativa. (RTCA 67.04.50:08 Alimentos. Criterios Microbiológicos para la Inocuidad de Alimentos).
En figura 14 se observa la incidencia de la contaminación por presencia de Listeria monocytogenes. De un total de 82 muestras analizadas para el aislamiento e identificación de la bacteria, sólo dos casos positivos, correspondiente al $2.44 \%$, observados para los municipios de Ilobasco y Ciudad Dolores. 
Tabla 5. Resultados de análisis Identificación de E.coli, en queso fresco durante la etapa II de análisis

\begin{tabular}{|l|c|c|c|c|}
\hline \multirow{2}{*}{ Municipio de Cabañas } & \multicolumn{5}{|c|}{ E. coli } \\
\cline { 2 - 5 } & $0-100$ UFC/g & $\begin{array}{l}101-\quad 1,000 \\
\text { UFC/g }\end{array}$ & $\begin{array}{l}1,000-10,000 \\
\text { UFC/g }\end{array}$ & $<10,000$ UFC/g \\
\hline Cinquera & 8 & 0 & 0 & 0 \\
\hline Dolores & 3 & 5 & 0 & 2 \\
\hline Guacotecti & 8 & 0 & 0 & 0 \\
\hline Ilobasco & 15 & 0 & 0 & 1 \\
\hline Jutiapa & 8 & 0 & 0 & 0 \\
\hline San Isidro & 8 & 0 & 0 & 0 \\
\hline Sensuntepeque & 8 & 0 & 0 & 0 \\
\hline Tejutepeque & 8 & 0 & 0 & 2 \\
\hline Victoria & 5 & 1 & 0 & 5 \\
\hline Total casos & 71 & 6 & 0 \\
\hline
\end{tabular}

Presencia / Ausencia de

Listeria monocytogenes

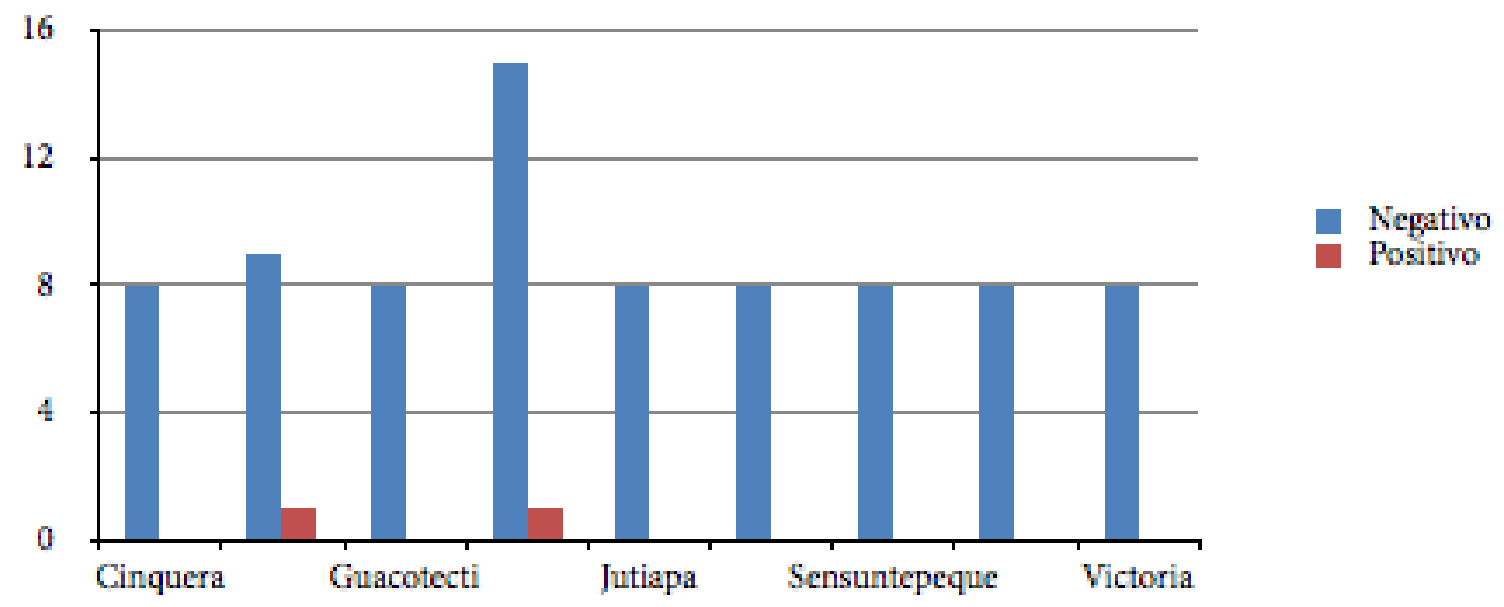

Figura 14. Comportamiento de la detección de Listeria monocytogenes en queso fresco artesanal. 


\section{Conclusiones}

Este estudio permite conocer el estado de inocuidad relacionado con su análisis microbiológico, en el que los productos lácteos artesanales frecuentemente suelen estar. Es importante reconocer aspectos primordiales que forman parte de la elaboración del producto, es decir, la importancia de la calidad de la materia prima durante el proceso y obtención del producto final.

El queso fresco artesanal es elaborado con leche cruda de vaca, cuajo y sal; no obstante, durante el proceso de obtención, la leche no es pasteurizada. A falta de tinas de cuajo, este proceso se realiza en depósitos caseros que no siempre son de exclusivo uso del proceso del queso fresco. En muchas ocasiones la leche no pasteurizada suele estar expuesta a contaminación por vectores y otras bacterias ambientales, sumado a las prácticas higiénicas del proceso. Pero este último factor no siempre es el responsable de la presencia de Listeria monocytogenes, puesto que aún ha sido encontrado en leches cuyos recuentos bacterianos han resultado ser bajos.

Sin embargo, el $\mathrm{pH}$ en quesos blandos puede alcanzar niveles superiores a 6.5, lo cual favorece el desarrollo rápido de la bacteria. (Fenlon et al. 1989). Por otra parte se pone de manifiesto que los resultados negativos en el aislamiento de bacteria pueden relacionarse con la acidificación de la masa del queso por producción de ácido láctico, como uno de los factores principales en la inhibición o destrucción de microorganismos patógenos. Listeria monocytogenes, tiene la capacidad de resistir a valores de $\mathrm{pH}$ de 5.0 o más bajo (Buchanan y otros 1989).
De las 82 muestras analizadas, se logró aislar seis siembras en agar Oxford, que cumplieron con la característica típica de los agares cromogénicos. De estas, sólo dos muestras (2.44\%), correspondieron a las características de Listeria monocytogenes. Estos resultados positivos corresponden a una posible contaminación durante el proceso de elaboración del queso artesanal, o leche cruda sin procesar durante algunas horas, produciendo un aumento en la acidificación de las bacterias lácteas, debido a que forma parte de la flora normal de leche.

Además de la identificación de Listeria monocytogenes, se encontraron otras bacterias, por ejemplo: E. coli, se encontró que diecinueve casos de 149 (12.75\%), reportaron niveles fuera de los establecidos por la normativa RTCA 67.04.50:08. Al estudiar estos datos se corroboró la necesidad de los productores en establecer procedimientos de higiene del personal y durante la elaboración del queso fresco, ya que si bien es cierto que puede encontrarse en un número menor a $10 \mathrm{UFC} / \mathrm{g}$, debe procurarse inhibir su crecimiento por medio de prácticas adecuadas para el proceso mismo.

Luego del proceso de obtención del queso fresco, se comercializa comúnmente en el lugar donde se elabora, pero en otras ocasiones se traslada a los puntos de venta de mercados municipales, donde en algunas ocasiones poseen almacenamiento en refrigeración, y en otras, se expone a la vista del consumidor. En el manejo del producto se pueden generar diversas acciones donde la adhesión de la bacteria ocurre de manera natural; por esto, el manipulador de alimentos se convierte además en una de las causas más frecuentes de contaminación, pero de bacterias entéricas. El no contar con prácticas adecuadas puede repercutir de forma directa en el alimento. 
Es importante crear un precedente en el registro de productos lácteos de la zona, la influencia en la producción de estos alimentos se convierte en una fuente importante de crecimiento económico y de sostenimiento familiar, de manera que el conocer los resultados puede llevar a crear mejores procesos; pero sobre todo, establecer parámetros en la zona. Esto representa un punto de partida en términos de inocuidad, y del potencial de crecimiento para muchos de los productores, aunque la adopción de medidas de higiene se vuelve un compromiso bilateral entre profesionales del área de alimentos, y los productores de alimentos en la implementación de las mismas medidas y prácticas adecuadas de manufactura.

La población del departamento de Cabañas suele consumir diferentes tipos de quesos de procedencia artesanal: primero por ser más asequible a la economía de la familia; y en segundo término, por tener preferencia en los productos lácteos de este tipo. Ello compromete también a crear programas de seguimiento donde se evalúen todos los factores intrínsecos a la inocuidad, a fin de generar propuestas prácticas para los productores artesanales que les lleve a concientizarse sobre la importancia que tiene el ofrecer alimentos saludables y seguros.

Para próximas investigaciones, los datos expresados en este informe, servirán como precedentes y como datos para aquellos productores que, en un futuro próximo, lleven a cabo la conformación de cooperativas de alimentos. Cabe destacar que la calidad de los alimentos ofrecidos está ligada a todos los factores que no favorecen a la inocuidad de los productos lácteos, en especial los quesos blandos y otros productos con actividad de agua elevada.
Es de especial interés para los estudiantes del sector Agroindustrial, tomar en cuenta que el desarrollo en el área láctea provee desarrollo e innovación; pero que, al tecnificar los procesos en la cadena productiva, deben de establecerse estándares que permitan implementar sistemas de gestión de la calidad. Es importante en este sentido preocuparse por el desarrollo humano social, para aportar conocimiento técnico a los productores artesanales y promover el desarrollo de la zona del departamento de Cabañas.

Las autoridades correspondientes en el área de la Salud deben de conocer este tipo de resultados, que les conduzcan a crear mecanismos de inspección a los productores del sector alimenticio, en especial del área de lácteos, para fortalecer todos los aspectos que hoy día carecen de control y seguimiento a la calidad: partiendo desde la cadena productiva, que inicia en los hatos productores de leche, hasta la comercialización de los productos en mercados municipales.

De existir un proyecto de ayuda y cooperación al productor Agroindustrial, es necesaria la creación de organismos en donde se involucren expertos en el tema de productividad, calidad e inocuidad alimentaria; sin menoscabar el asocio que debe existir entre la empresa y la academia. 


\section{Referencias}

Albarracín, F. et al (2006). Estimación de la proporción de Listeria monocytogenes y Salmonella spp en quesos frescos (queso de hoja, cuajada) y queso Doble Crema producidos y comercializados en el Municipio de Pamplona, Norte de Santander. ISSN: 0120-4211.

Anon. (1997). Guidelines for Good Hygienic Practice in the Manufacture of Chilled Foods, 3rd. edn. Chilled Food Association, London.

Bell, Ch.; Kyriakides, A. (1998). Listeria: una aproximación practica al microorganismo y su control en los alimentos. Zaragoza, Editorial Acribia, pág. 50-55, 145, 147.

Bachmann H. y Spahr U. (1995). The fate of potentially pathogenic bacteria in Swiss hard and semi hard cheeses made from raw milk. Pages: 476-439.

Codex Alimentarius, (2007). Directrices Sobre la Aplicación de Principios Generales de Higiene de los Alimentos para el Control de Listeria monocytogenes en los Alimentos. Recuperado de: http://www.codexalimentarius.net/search/advanced.do?lang=es

Donnelly, CW., et al (1992). Compendium of methods for the microbiological examination of foods. 3rd ed. Washington DC; American Public Health Association p. 637-663.

Espinoza, A., et al (2003). Determinación de Listeria monocytogenes en quesos frescos de producción artesanal que se expenden en los mercados del distrito de Ica.

Fenlon D. y Wilson J. (1989). The Incidence of Listeria monocytogenes in raw milk from farm bulk tanks in North East Scotland. Appl. Bacteriology.

Greenfield, H. y Southgate, D. (1992). Food Composition; Production, management and use. Sampling. London, Elsevier Applied Science. Chapter 6.

Gallegos J., et al (2007). Frecuencia de Listeria spp. En quesos colombianos Costeños. Rev. Mvz. Córdoba.

Hitchins A., (1995). Listeria monocytogenes In Food and Drug Administration. Bacteriological Analytical Manual. 8th ed. Arlington: AOAC Internation; pp. 10.01-11.08.

International Commission on Microbiological Specifications for Foods. (1996) Microorganisms in Foods. 5. Microbiological Specifications of Food Pathogens. Blackie Academic \& Professional, London.

Jeong, D.; Frank, J. (1994). Growth of Listeria monocytogenes at $10{ }^{\circ} \mathrm{C}$ in biofilms with microorganisms isolated from meat and dairy processing enviroments. Journal of Food Protection pp 224-227. 
Martino T., et al (2005). Determinación de Listeria spp, en Quesos y Embutidos Comercializados en Cuba; Instituto de Nutrición e Higiene de los Alimentos. INHA.

Mossel D., et al (1995). Essentials of the Microbiology of Foods. A Textbook for Advanced Studies. John Wiley \& Sons Ltd, New York.

Ramírez E., y Pineda S. (2010). Aislamiento de Listeria monocytogenes en productos lácteos, artesanales y hortalizas. Revista Ciencia y Tecnología, Latín América Journals online. Recuperado de: http://www.lamjol.info/index.php/RCT/article/view/1802/1607

Schöbitz R., et al (2001). Presencia de Listeria monocytogenes en leche cruda y quesos frescos artesanales. Instituto de Ciencia y tecnología de los Alimentos, Instituto de Producción y Sanidad Vegetal, Facultad de Ciencias Agrarias, Universidad Austral de Chile. ISSN: 0304-8802.

Schöbitz R., Ciampi L. y Nahuelquin Y. (2009). Listeria monocytogenes, Un peligro Latente para la Industria de Alimentos. Instituto de ciencia y Tecnología de Alimentos, Instituto de Producción y sanidad Vegetal, Facultad de Ciencias Agrarias, Universidad Austral de Chile.

Reglamento Técnico Centro Americano 67.04.50:08 (2012). Alimentos. Criterio Microbiológico para la Inocuidad de Alimentos. Recuperado de http://www.ccit.hn/wp-content/ uploads/2014/08/Anexo-resolucion-No.283-2012-aditivos-alimentarios.pdf

Sánchez, B. y Palencia H., E. (2010). Infecciones por Listeria monocytogenes. Hospital Infanta Leonor, Madrid España. 